\title{
Field Experiment Research of the Polycystic Aeration Bolt: Model Design and Anchorage Mechanism
}

\author{
Wen Xiang Peng, ${ }^{1}$ Ming Kai Xu, ${ }^{1}$ Yi Fan Chen $\mathbb{D}^{2}{ }^{2}$ Zheng Hao Chen, ${ }^{3}$ and Zhuo Yang ${ }^{4}$ \\ ${ }^{1}$ School of Geosciences and Info-Physics, Central South University, Changsha, Hunan 410083, China \\ ${ }^{2}$ School of Resources and Safety Engineering, Central South University, Changsha, Hunan 410083, China \\ ${ }^{3}$ CISDI Engineering Co., Ltd., Chongqing 400013, China \\ ${ }^{4}$ Guangzhou Institute of Building Science Co., Ltd., Guangzhou 510440, China \\ Correspondence should be addressed to Yi Fan Chen; 1051361824@qq.com
}

Received 27 November 2020; Revised 11 December 2020; Accepted 1 January 2021; Published 18 January 2021

Academic Editor: Xingzhou Chen

Copyright $\odot 2021$ Wen Xiang Peng et al. This is an open access article distributed under the Creative Commons Attribution License, which permits unrestricted use, distribution, and reproduction in any medium, provided the original work is properly cited.

\begin{abstract}
As a new type of bolt, the polycystic aeration bolt has a broad application prospect in soft soil area; however, its design and production are still in the stage of constant exploration and improvement. From the perspective of bolt material and engineering cost, the important components of the polycystic aeration bolt were analyzed by combination with the existing bolt models, and a new structural design scheme of a kind of polycystic aeration bolt which can be used in practical engineering was presented in this paper. Then, the stress and failure mode of this bolt were discussed, and the theoretical equation of the bearing capacity was derived by using the elastic-plastic theory. In addition, the assembly and fabrication technology of this bolt in practical foundation pit engineering was described in detail. Finally, the field pull-out test of the polycystic aeration bolt was carried out, and the test results were compared with those of the conventional grouting bolt, which indicated that this new bolt has a greater advantage in bearing capacity than the conventional grouting bolt, verifying the feasibility of the structural design scheme of the polycystic aeration bolt proposed in this paper.
\end{abstract}

\section{Introduction}

China has a vast territory with complex and diverse geological and geomorphic conditions [1,2], where soft soil layers are widely distributed, such as in the areas of Shanghai, Wuhan, and Nanjing in the Yangtze River basin and Guangzhou in the Pearl River Delta [3-5]. Geologically, soft soil layer is characterized by high natural water content, large pore ratio, high compressibility, low shear strength, and high sensitivity, which makes it an undesirable geological body in constructional engineering [6-10]. The rapid development of China's economics put forward higher and higher requirements for the construction of urban architecture, transportation, and others, and the majority of the engineering construction cannot do without the foundation pit support [11-15]. There are numerous supporting forms for foundation pit, among which pile-anchor support is the most commonly used [16-20], whereas it plays small role in soft soil layer, because the bonding strength between soft soil and bolt body is low and the bolt can provide low pulling resistance due to the special properties of soft soil, which therefore leads to overlong bolt and dense spacing of bolts in soft soil foundation pit. On the one hand, the bolt length is limited in the denser parts of the architectural complex, and the overlong bolt and dense spacing will make it expensive. On the other hand, the foundation pit is a temporary support, and the bolts will no longer function when the foundation pit is backfilled, in which case the bolts left in the stratum not only are an economic waste but also leave a hidden safety hazard. In response to the above anchorage problems in soft soil layer, a new type of bolt, the polycystic aeration bolt $[21,22]$, was proposed, which was achieved by installing several rubber films on the hollow bolt. By aerating the rubber film to form the expansion anchorage section, it 
can effectively improve the bearing capacity of the bolt, control the structural deformation, and increase the shear strength of the surrounding soil, which brings a positive impact on the bolt support in soft soil area $[23,24]$. Since the anchorage force is provided once the rubber film is aerated, it can save construction time compared with grouting bolt. When the foundation pit construction is completed, the air in the rubber film can be drained, and the bolt can be pulled out for reuse, saving the cost [25].

At present, numerical simulation and laboratory test are widely used in geotechnical engineering [26-29], the research on this new bolt is still in the laboratory test stage, the field test has not been implemented [30], and the anchorage performance of the bolt in the actual foundation pit engineering in soft soil layer has not been verified yet. To apply this new bolt into practical application, give full play to its advantages different from the ordinary bolt, and provide the theoretical support and design basis, this paper proposed a new polycystic aeration bolt design by optimizing the structure size and the assembly materials of existing bolt production technology and conducted experimental studies, analyzed the corresponding mechanical model and anchorage mechanism, and compare the anchorage efficacy with grouting bolt through field pull-out tests, which verified the feasibility of the proposed bolt.

\section{The Design of the Polycystic Aeration Bolt}

The polycystic aeration bolt is composed of control device (valve and pressure gauge), bolt body, airbags, and seal element (see Figure 1). As previously described, this bolt utilizes air pressure to expand airbags and squeeze the surrounding soil to form a cavity, that is, anchorage section, so it is suitable for temporary foundation pit support in soft soil area, and the research on this new type bolt has significant engineering value.

As one of the important parts of the polycystic aeration bolt, the bolt rod mainly serves as a force transmission member to transfer the soil pressure to each airbag. It not only needs to bear the bearing capacity of the whole bolt but also is the air inlet channel of the airbag, so hollow components must be used for the bolt rod. Therefore, the seamless steel tube with an outer diameter of $54 \mathrm{~mm}$ and a wall thickness of $5 \mathrm{~mm}$ was selected, and the cross-sectional area is $770 \mathrm{~mm}^{2}$ and the corresponding ultimate tensile strength was up to $284.9 \mathrm{kN}$, which meets the requirements of the bolt design. Airbag is the module providing anchorage force for the bolt and makes high requirements on the airbag material, such as elastic performance, wear resistance, water tightness and air tightness, friction performance with soil, membrane strength, and the ability to prevent piercing from sharp objects. Based on previous studies, the Brand IIR1751 butyl rubber was preferentially considered as the material for airbag production, and the thickness of $4 \mathrm{~mm}$ was determined. The maximum inflation pressure is $1500 \mathrm{kPa}$, the maximum elongation $\leq 350 \%$, and the expansion rate $\leq 2.0$. The stainless steel throat band is the connection between the airbags and the bolt rod, which ensures the airtightness of airbag and the tight connection between airbags and rod by

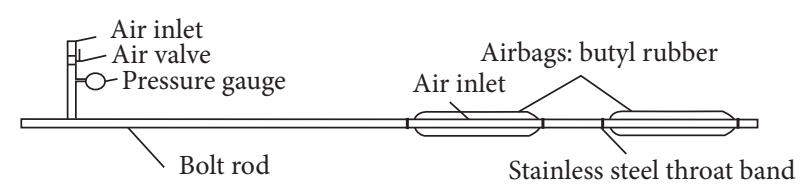

Figure 1: The polycystic aeration bolt module.

providing the grip force. Meanwhile, it transfers the anchorage force of airbag to the bolt rod by the friction between rubber and rod. Single stainless steel throat band is difficult to meet the requirements; thus multiple stainless steel throat bands were applied to work together. The control device is the aeration switch and the state observation device of the bolt. Through the observation of the change of the pressure gauge, it can indicate whether leakage failure emerges in the soft soil layer.

\section{The Anchorage Theory of the Polycystic Aeration Bolt}

3.1. Stress and Failure Mode of the Bolt. According to the architectural feature of the polycystic aeration bolt, the anchorage force of the polycystic aeration bolt consists of three parts [31] (see Figure 2): (1) friction resistance between airbags and soil mass $T_{1}$, (2) tip resistance of airbags $T_{2}$, and (3) friction resistance between bolt rod and soil mass $T_{3}$. Since $T_{3}$ is small and has little influence on the anchorage force in soft soil layer, it was ignored in this study.

Airbags are connected with bolt rod by throat bands (Part 1 and Part 2 in Figure 2), and Part 1 provides the friction between the airbags and bolt rod, by which the external force $T$ is transmitted from bolt rod to airbags. The incompressibility of water causes friction resistance and tip resistance between airbags and soil, which is basically in equilibrium with external force. From the above, the polycystic aeration bolt belongs to tension bolt, with two failure modes [32]: (1) bolt failure, including airbag damage, bolt fracture, and airbag-bolt separation, and (2) soil failure, yield failure of soil mass at the tip of the expansive airbag.

3.2. Bearing Capacity Theoretical Equation. In the derivation process of the theoretical equation, the following assumptions were made:

(1) The airbag and the water were integrated and considered as elastic cylinders.

(2) The surrounding soil was elastic-plastic body and conformed to Mohr-Coulomb criterion.

(3) The axial stress was uniformly distributed, and the gravity and deformation of the bolt rod were ignored.

(4) The bolt meets the strength requirement, and the failure mode was the yield failure of soil.

The bearing capacity of a single airbag is composed of $T_{1}$ and $T_{2}$, which can be deduced based on the theoretical results of previous studies: 


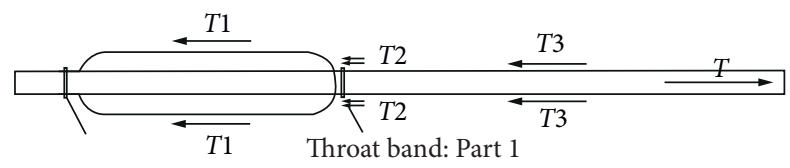

Throat band: Part 2

Figure 2: Force analysis of the polycystic aeration bolt.

$$
\begin{aligned}
P & =T_{1}+T_{2}, \\
T_{1} & =\int_{0}^{l} 2 \pi R \tau_{x} \mathrm{~d} x=\left[P-\pi\left(R^{2}-r^{2}\right) \sigma_{p}+\frac{\pi R^{2}}{k} c\right] \cdot\left(1-e^{-(2 k l / R)}\right) \\
T_{2} & =\pi\left(R^{2}-r^{2}\right) \sigma_{p} .
\end{aligned}
$$

Then,

$$
P=\pi\left(R^{2}-r^{2}\right) \sigma_{p}+\frac{\pi R^{2} c}{k}\left(e^{2 k l / R}-1\right) .
$$

Due to the polycystic structure of this bolt, the interaction between airbags causes the total bearing capacity which is not the pure superposition of the bearing capacity of single airbag, in which case the airbag influencing factor $\alpha$ was proposed to simplify such interaction. It ranges from 0.5 to 1 , and the specific value can be determined according to field test. Hence, the total bearing capacity of the bolt can be expressed as

$$
P_{n}=\alpha n\left[\pi\left(R^{2}-r^{2}\right) \sigma_{p}+\frac{\pi R^{2} c}{k}\left(e^{2 k l l R}-1\right)\right],
$$

where $R$ and $r$ are, respectively, the airbag radius and the maximum contact radius between airbags and soil mass; $\tau_{x}$ is the shear stress at a point on the contact surface between the airbag and the soil mass; $P$ is the external force acting on the bolt; $l$ is the length of airbag; $n$ is the number of airbags; $\sigma_{p}$ is the tip resistance of airbag.

\section{The Engineering Application of the Polycystic Aeration Bolt in Soft Soil Layer}

Field test is a research method that is closest to the practical engineering application environment. The field test of the polycystic aeration bolt is an important link in the application of the theoretical research to practice. The correctness of the theoretical research can be verified through the test process, and the existing problems between the theory and practice can be found, which can provide ideas and directions for the subsequent research work.

4.1. Field Fabrication Process of the Polycystic Aeration Bolt. The field test was carried out in a foundation pit construction site in Zhongshan city, Guangdong Province. In this test, the pull-out test was executed on two groups of the polycystic aeration bolts with different number of airbags. Also, a group of pull-out tests on grouting bolts was designed for comparison. The specific test strategy is presented in Table 1 , wherein the anchorage length of the polycystic aeration bolt is the sum of the length of the airbags and the airbags spacing.

Referring to the structural design of the polycystic aeration bolt in Section 2, the relevant bolt materials were prepared (the specific parameters of each material are presented in Table 2), and the field fabrication of the polycystic aeration bolt was implemented.

\subsubsection{Field Fabrication Process}

(1) Steel tube processing. According to the design requirements of the bolt, the bolt length is $12 \mathrm{~m}$, while the length of each steel tube in field is $6 \mathrm{~m}$. Thus, two steel tubes were welded by electric welding. The polycystic aeration bolt needs to be strictly sealed, which was achieved by welding steel plate at the end of bolt (see Figure 3).

Before installing airbags on the steel tube, water channel must be set beforehand, including the water injection port to the bolt and the water intake ports between steel tube and airbags. The former was used for connecting control device (see Figure 4), and the latter were finished by arranging 4 ports for each airbag ( 2 ports on each side of the tube).

(2) Bolt assembly. In accordance with the previously described bolt collocation pattern, airbags were installed on the bolt rod, both ends of the airbag were fixed and sealed with stainless steel throat bands, and the joints were wrapped in tape, which can prevent stainless steel throat band from damaging rubber and further improve the air tightness of bolt (the finished product is shown in Figure 4).

(3) Water injection test. To examine the tightness of the polycystic aeration bolt, the water injection test was carried out on the site. The water injection pipe was connected to the control device (see Figure 5), the water valve was opened, and the bolt was injected with water.

During the test, the airbags close to the control device showed obviously expansion, while the others 
TABLE 1: The test strategy of pull-out test in situ.

\begin{tabular}{lccccccc}
\hline The polycystic & $\begin{array}{c}\text { Airbag length } \\
(\mathrm{mm})\end{array}$ & $\begin{array}{c}\text { Airbag thickness } \\
(\mathrm{mm})\end{array}$ & $\begin{array}{c}\text { Burial depth } \\
(\mathrm{m})\end{array}$ & $\begin{array}{c}\text { Airbag } \\
\text { number }\end{array}$ & $\begin{array}{c}\text { Airbag spacing } \\
(\mathrm{mm})\end{array}$ & $\begin{array}{c}\text { Bolt length } \\
(\mathrm{m})\end{array}$ & $\begin{array}{c}\text { Airbag diameter } \\
(\mathrm{mm})\end{array}$ \\
aeration bolt & 500 & 4 & 4.5 & 2 & 500 & 12 & 12 \\
& 500 & 4 & 4.5 & 4 & 500 & 150 \\
\hline \multirow{2}{*}{ The grouting bolts } & Bolt length $(\mathrm{m})$ & $\begin{array}{c}\text { Bolt diameter } \\
(\mathrm{mm})\end{array}$ & $\begin{array}{c}\text { Burial depth } \\
(\mathrm{m})\end{array}$ & Grouting length $(\mathrm{m})$ & Trepanning diameter $(\mathrm{mm})$ \\
& 12 & 28 & 4.5 & & 3.5 & 130 \\
\hline
\end{tabular}

TABLE 2: The specific parameters of bolt materials.

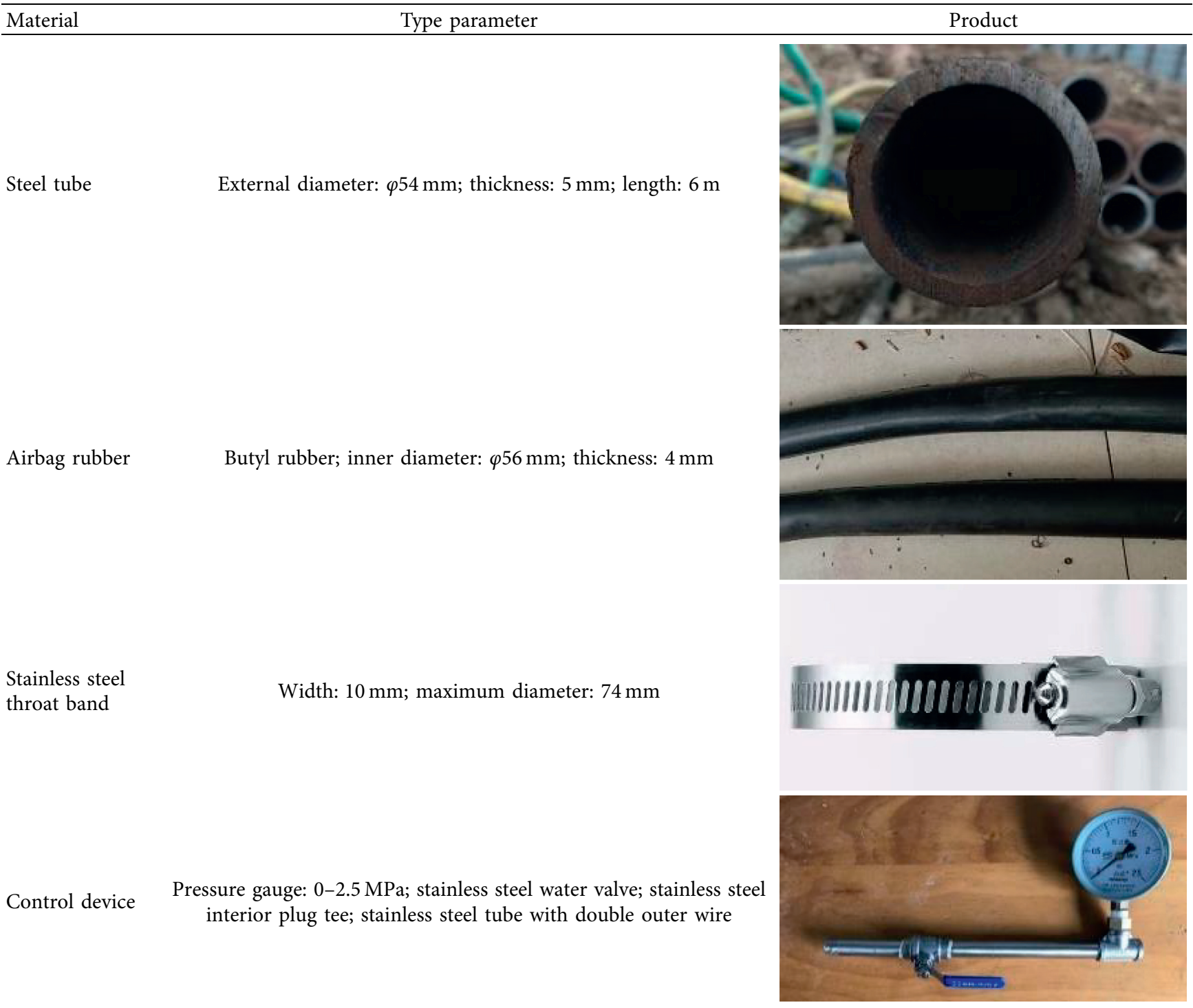

have hardly expanded (see Figure 6). Through the discussion with the field technicians, the causes of differential expansion were analyzed, and the following conclusions and treatment methods were obtained. In the course of water injection, the water pressure of the airbags close to the control device was greater than that of the ones far away, on which rubber has little restraint, leading to the fact that the water pressure cannot be transferred to the distant airbags, and therefore differential expansion of airbags emerged. To cope with this problem, the plastic hose with the diameter of $150 \mathrm{~mm}$ was applied (see Figure 7). When the diameter of expanded airbag close to the control device reaches the diameter of the plastic hose, the airbag cannot continue to expand due to the limitation of the hose, and then the water pressure will be transferred to the next airbag. Besides, the plastic hose can not only make each airbag 


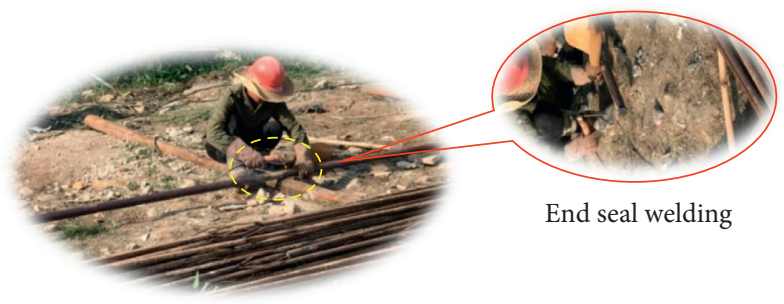

FIGURE 3: Electric welding process of steel tube.

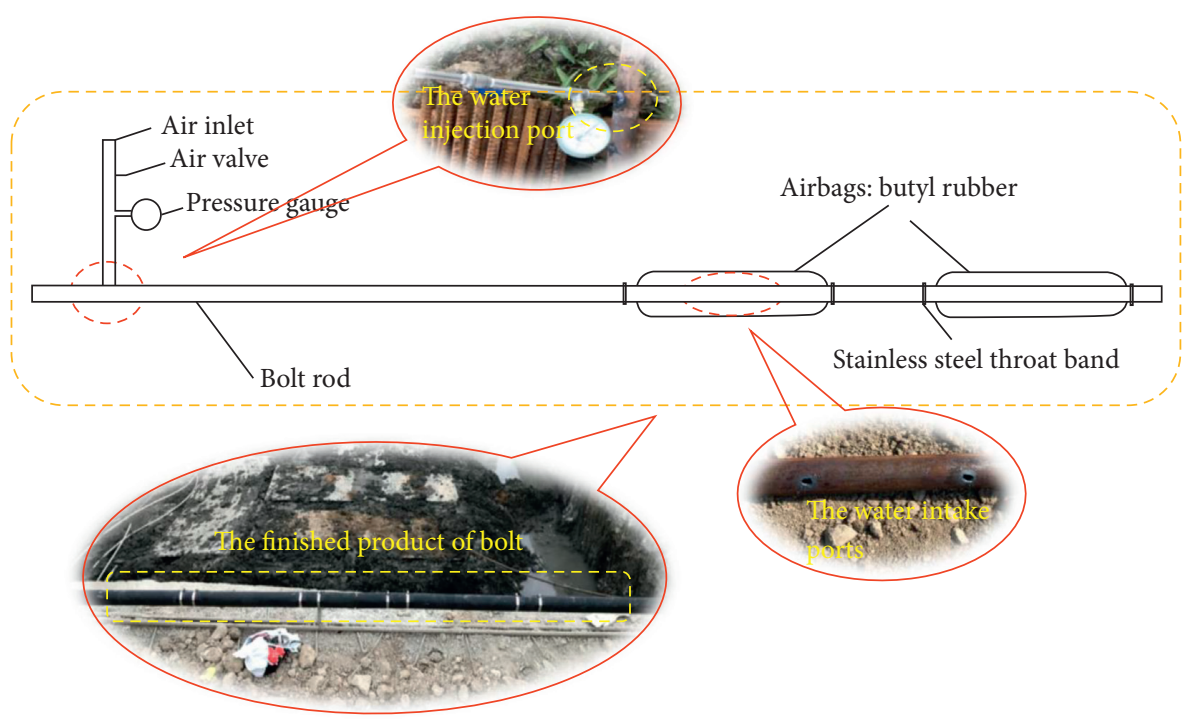

Figure 4: Product of the polycystic aeration bolt.

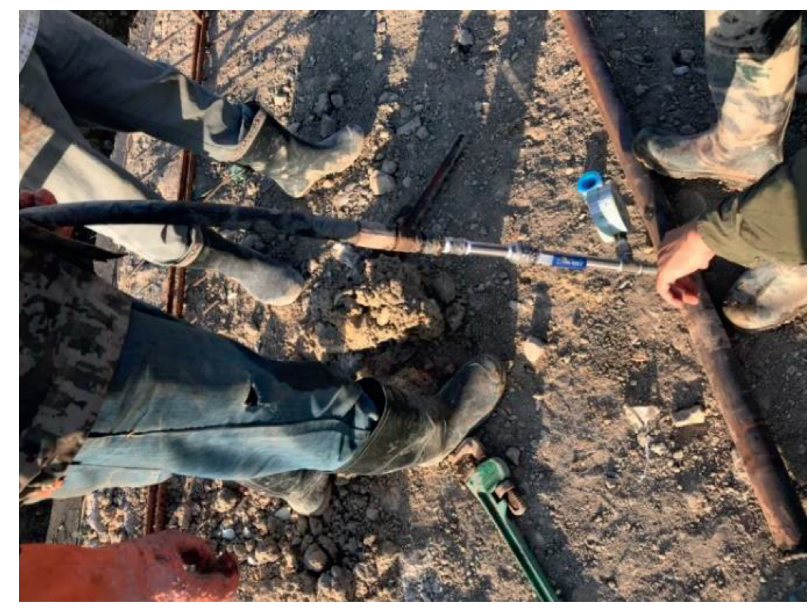

FIgURE 5: Water injection test process.

expand uniformly but also protect the rubber. Moreover, the friction coefficient between the surface of plastic hose and the surface of rubber is not much different, so the setting of plastic hose will not have a great impact on the lateral friction resistance of the airbags in the soil.
After applying the plastic hose to the bolt, the water injection test was reconducted. As shown in Figure 8, the airbags have expanded uniformly, and then the plastic hose was removed after water injection was completed, for better observation to the effect. 


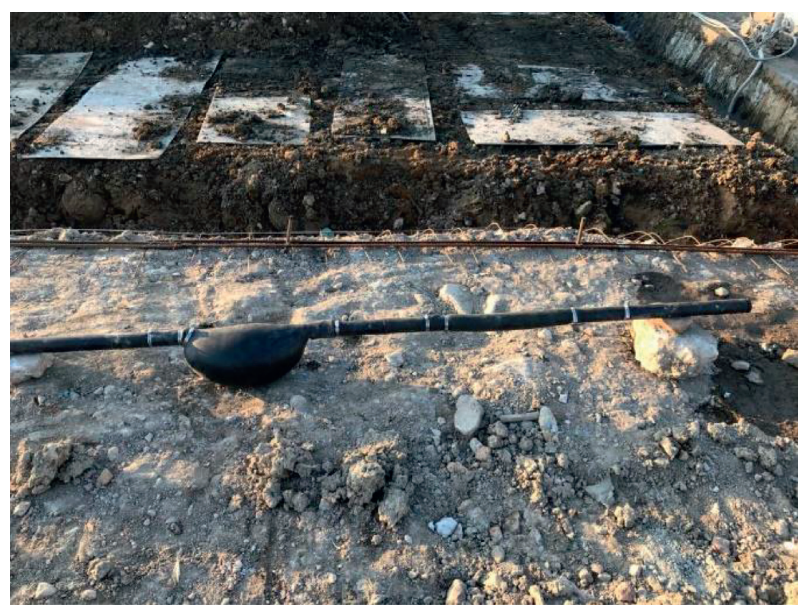

FIgURE 6: Differential expansion of airbags.

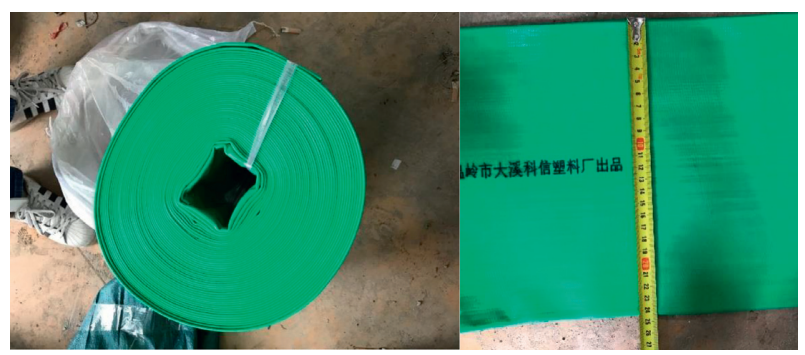

FIgUre 7: The plastic hose.
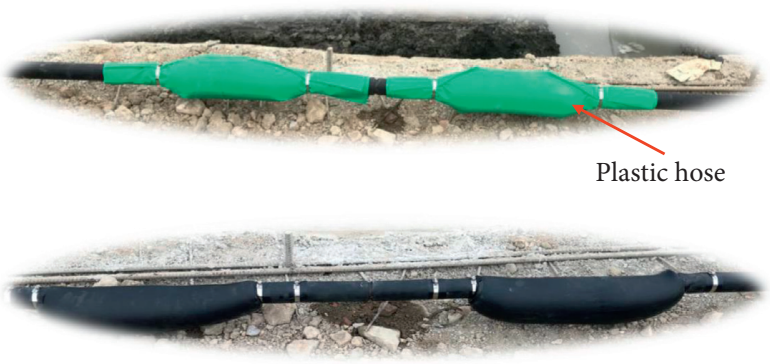

FIgURE 8: The expanding effect of the airbags with plastic hose.

(4) Pull-out steel welding. To facilitate the pull-out test, a threaded steel bar $(500 \mathrm{~mm}$ in length and $28 \mathrm{~mm}$ in diameter) was welded at the end of the bolt (see Figure 9).

\subsection{Conditions of Test Site}

4.2.1. Project Profile. Located in Ganglong South Road, Shalang Town, Zhongshan City, Guangdong Province, the project plans to build a residential building. The site covers an area of 73,100 square meters, with 1-2 floors of basements. The foundation pit is supported by double rows of deep mixing piles + anchor rod/anchor cable. In the design, the full-length grouting bolt is $12 \mathrm{~m}$ in length, the designed

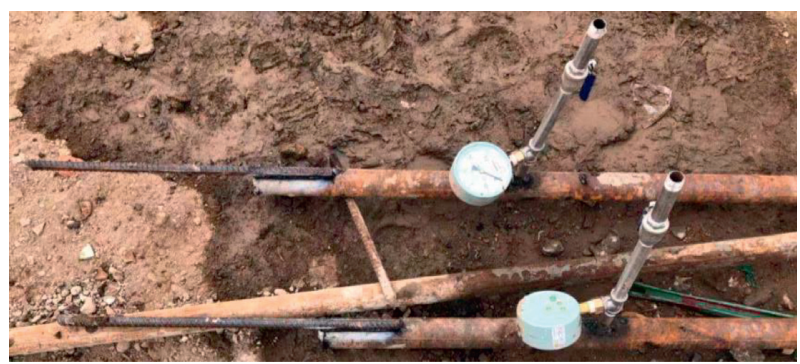

FIgURE 9: Threaded steel bar welding.

pulling force is $40 \mathrm{kN}$, the horizontal spacing is $800 \mathrm{~mm}$, and the vertical spacing is $800 \mathrm{~mm}$.

4.2.2. Formation Conditions. There are mainly the following layers in the site: artificial fill soil, silty clay, muddy soil, silty sand, and sandstone, and the muddy soil was selected as the test layer. The characteristics of the muddy soil in the site are as follows: dark gray/gray, saturated, soft plastic, containing a small amount of organic matter and fine sand, with an average layer thickness of $9.78 \mathrm{~m}$. The geotechnical physical properties are presented in Table 3.

4.3. Field Pull-Out Test. The test procedure on the polycystic aeration bolt includes drilling hole, bolt placement, water injection, and pull-out test. Since the bolt expands the airbags by water pressure to provide pulling resistance, the best diameter of borehole should be equal to the maximum diameter of the bolt. Considering practical problems such as bolt placement, muddy soil layer shrinkage, and site equipment, the final borehole diameter was determined to be $90 \mathrm{~mm}$. The other parameters were $11 \mathrm{~m}$ in length and $10^{\circ}$ in angle, and the trepanning was implemented by crawler bolt drilling machine (see Figure 10).

Then, the bolt was manually inserted into the hole, and quantitative water injection was used. According to the number of airbags, the volume of the water needed when airbag diameter is expanded to $150 \mathrm{~mm}$ was calculated, and the water was injected into the bolt through the water pump (see Figure 11) from the water storage tank (see Figure 12).

The test procedure on the conventional grouting bolt is drilling hole, bolt placement, borehole grouting, bolt maintenance, and pull-out test. The bolt was made of $28 \mathrm{~mm}$ diameter threaded reinforcing steel bar, and the center bracket was arranged (see Figure 13). It also adopted the crawler bolt drilling machine to form holes with a diameter of $130 \mathrm{~mm}$. Since the designed anchorage length is $3.5 \mathrm{~m}$, quantitative grouting was also applied during borehole grouting, and 10 days of maintenance were needed before the pull-out test.

The tests on both bolts were completed via utilizing hydraulic jack bolt drawing equipment (see Figure 14), which is to obtain the maximum bearing capacity and the corresponding displacement of the bolts. Therefore, the steploading was used to record the loading amount and displacement of each step. Criteria of bolt failure are shown as follows: 
TABLE 3: The geotechnical physical properties of muddy soil in the site.

\begin{tabular}{lccccc}
\hline Type & State & Weight $\left(\mathrm{kN} / \mathrm{m}^{3}\right)$ & Cohesion $(\mathrm{kPa})$ & Friction $\left(^{\circ}\right)$ & Characteristic value of friction resistance $(\mathrm{kPa})$ \\
\hline Muddy soil & Soft plastic & 18 & 10 & 8 & 14 \\
\hline
\end{tabular}

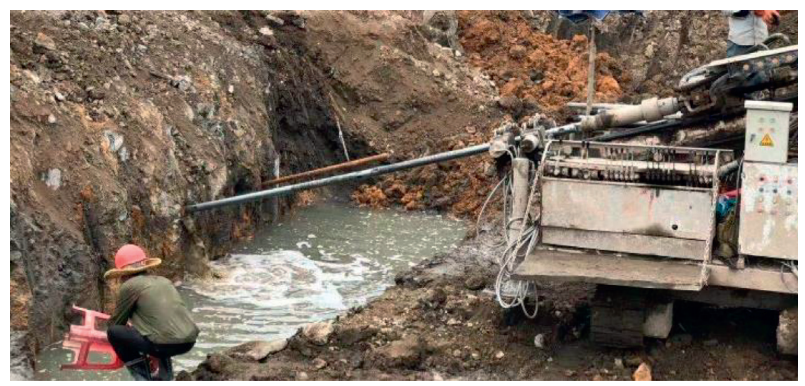

FIGURE 10: Field trepanning by crawler bolt drilling machine.

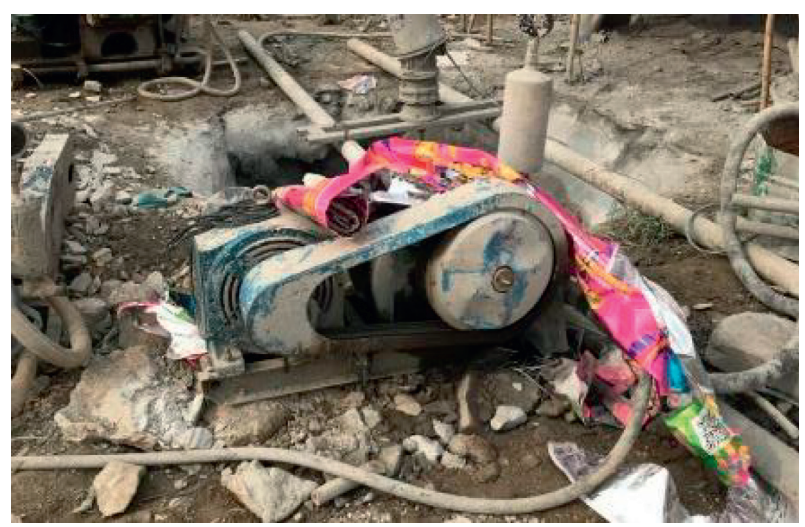

Figure 11: The water pump.

(1) The displacement is more than twice of the previous accumulated displacement when the next steploading was applied.

(2) The airbags were damaged and the pressure of the pressure gauge decreased significantly.

(3) Hydraulic jacks cannot continue to exert pressure effectively.

4.4. Bolt Recycle. Compared with the conventional grouting bolt, the biggest advantage of the polycystic aeration bolt is that it can be recycled. Since there is no special bolt recovery equipment, excavator was used on site to pull the bolt out of the hole (see Figure 15). Before pulling out, it should be noted to open the valve to drain water from the bolt. The key to the reuse of the polycystic aeration bolt lies in whether the airbags are damaged during supporting, and the bolts pulled out from the formation were checked out. As shown in Figure 16, the airbags are in good condition under the protection of the plastic hose, proving that the bolt could be recycled.

4.5. Analysis of Test Results. By comprehensively comparing the data obtained from field tests, the differences between the

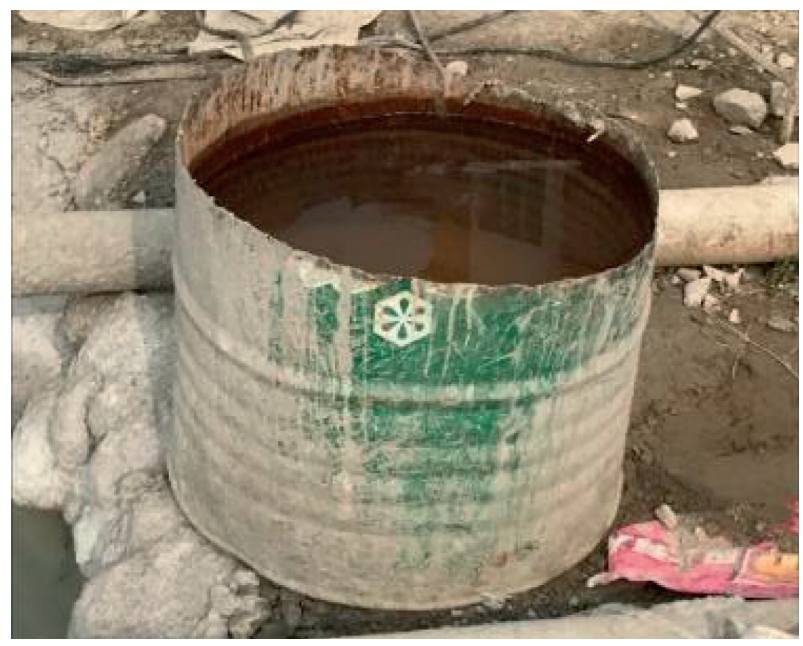

FIgURE 12: The water storage tank.

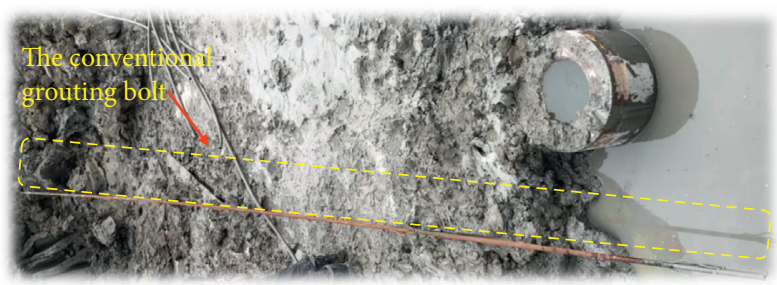

Figure 13: The conventional grouting bolt.

two types of bolts can be studied. After sorting out the data, the maximum bearing capacity and displacement of the polycystic aeration bolt and grouting bolt are shown in Table 4, and the relationships between pulling resistance and displacement are plotted in Figure 17.

The analysis indicates that the pulling resistance of the polycystic aeration bolt with 4 airbags is 1.5 times higher than that of the grouting bolt, while the maximum displacement of the former is magnified by $43.4 \%$ than that of the latter which reflects that the polycystic aeration bolt has advantages in pulling resistance and is weaker in displacement control. Such difference in displacement control can be attributed to the fact that the anchorage section of the polycystic aeration bolt is a flexible body composed of water and rubber bursa, while the anchoring section of the grouting bolt is cement mortar. Under the action of tension, the deformation of the bursa is greater than that of cement mortar, resulting in greater displacement of bolt. In practice, the displacement of the polycystic aeration bolt can be controlled by the method of applying pretension. In bearing capacity, the polycystic aeration bolt has increased the number of end resistance, and its anchorage section is 


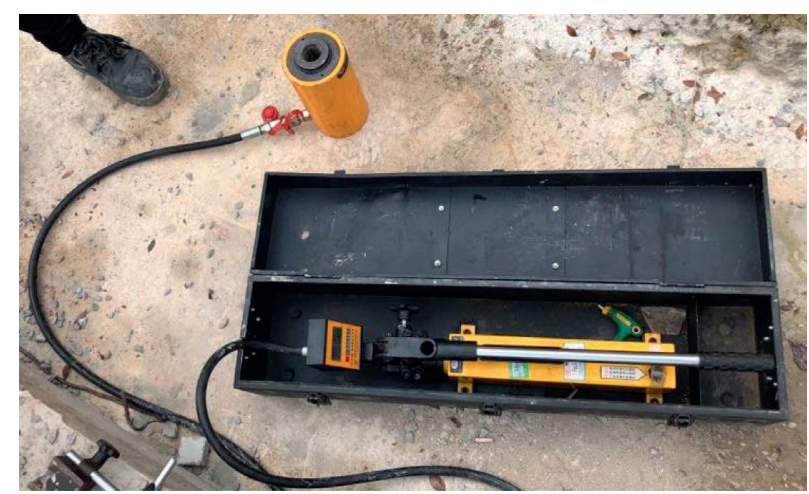

FIGURE 14: Hydraulic jack bolt drawing equipment.

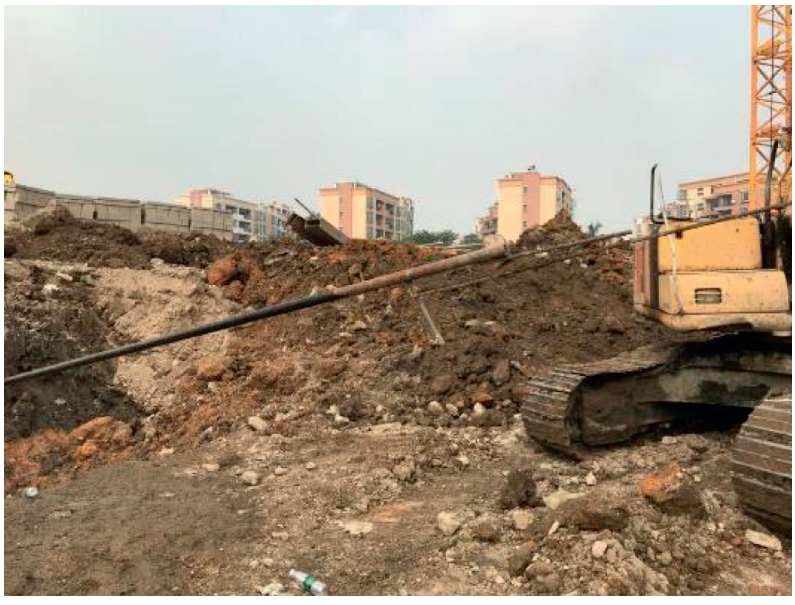

FIGURE 15: Recycle of the polycystic aeration bolt.

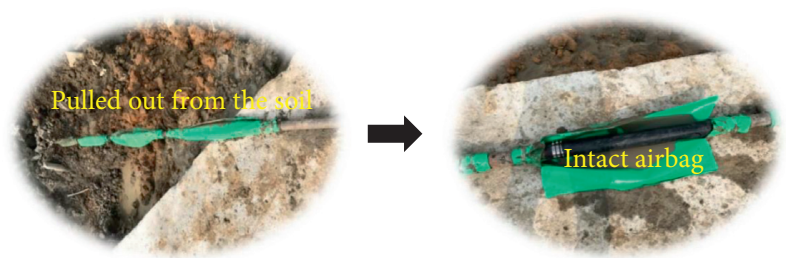

FIgURE 16: The stressed airbag in the formation.

TABLE 4: The bearing capacity and displacement of bolts.

\begin{tabular}{lccc}
\hline Number & Bolt type & Bearing capacity $(\mathrm{kN})$ & Displacement $(\mathrm{mm})$ \\
\hline 1 & The polycystic aeration bolt $(4$ airbags $)$ & 32.25 & 102.5 \\
2 & The polycystic aeration bolt $(2$ airbags $)$ & 15.56 & 125.7 \\
3 & The grouting bolt $(3.5 \mathrm{~m}$ anchorage length) & 21.52 & 71.5 \\
\hline
\end{tabular}

formed by extruding around soil which improves soil properties; as a result, the maximum bearing capacity of the polycystic aeration bolt is larger than that of grouting bolt.

On the other hand, the number of airbags is in favor of improving the performance of the polycystic aeration bolt.
According to Table 4, the polycystic aeration bolt with 4 airbags shows a 2.1-times increase in the maximum bearing capacity and $18.7 \%$ decrease in displacement, compared to those of the polycystic aeration bolt with 2 airbags. This is due to the increase of the airbags number, which increases 


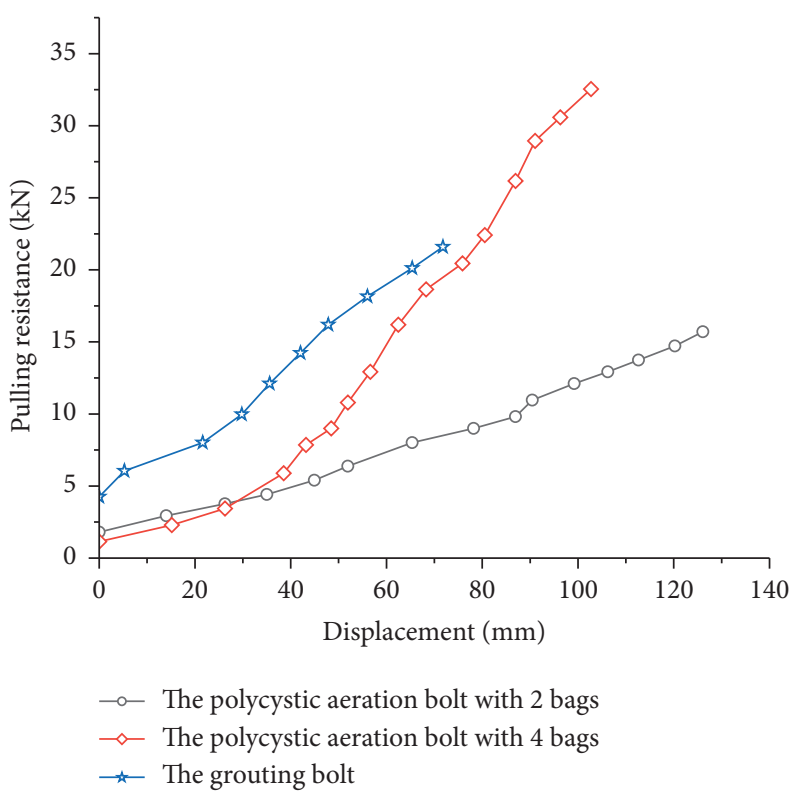

FIGURE 17: The relationships between pulling resistance and displacement.

the contact area between airbags and soil, causing corresponding increase of both the lateral friction resistance and the end resistance; that is, the soil has more restrictions on the bolt.

\section{Conclusions}

Based on the summary of the existing tests on the polycystic aeration bolt, this paper proposed a kind of polycystic aeration bolt that can be applied in practical engineering and then discussed the model design, anchorage mechanism, production process, product assembly, field test, anchorage effect and other aspects of this bolt. The conclusions are as follows:

(1) Considering the characteristics and material conditions of the polycystic aeration bolt, a structural design of this bolt was put forward, and the bolt rod, airbag rubber, seal fitting, and other accessories of the bolt were analyzed, which provides a basis for the later production and design improvement.

(2) The analysis of the stress characteristics and failure mode of this polycystic aeration bolt were made, and the theoretical equation of bearing capacity of the bolt was deduced according to Mohr-Coulomb criterion and elastic-plastic mechanics.

(3) The feasibility of the polycystic aeration bolt designed in this paper was verified through the field pull-out test, which can provide a larger bearing capacity in soft soil layer. Compared with grouting bolt, it has greater advantages.

\section{Notation}

$T_{1}$ : Friction resistance between airbags and soil mass

$T_{2}$ : Tip resistance of airbags

$T_{3}$ : Friction resistance between bolt rod and soil mass

$\alpha$ : The airbag influencing factor

$R:$ The airbag radius

$r$ : The maximum contact radius between airbags and soil mass

$\tau_{x}$ : The shear stress on the contact surface between the airbag and the soil mass

$P$ : The external force acting on the bolt

$l$ : The length of airbag

$n$ : The number of airbags

$\sigma_{p}$ : The tip resistance of airbag.

\section{Data Availability}

The data used to support the findings of this study are available from the corresponding author upon request.

\section{Conflicts of Interest}

The authors declare no conflicts of interest.

\section{Acknowledgments}

This paper gets its funding from Guangzhou Science Technology and Innovation Commission (201803030009). The authors wish to acknowledge this support.

\section{References}

[1] A. Khademalrasoul, A. Shirmohammadi, M. S. Pakbaz, and M. Labibzadeh, "Seismic soft soil-structure interaction using 
RLBRB-equipped strut in deep excavations," Journal of Earthquake Engineering, vol. 24, pp. 1-29, 2020.

[2] J. Chen, C. Lin, S. Liu, and H. Mo, "Study on supporting structure performance of deep soft soil foundation pit near sea under waves, tides, vibration, and unbalanced loads," $A d$ vances in Civil Engineering, vol. 2020, Article ID 8830199, 18 pages, 2020.

[3] H. Hu, B. Zhang, W. Yu, L. Lu, C. Zhang, and T. Niu, "Rheological behaviors of structural soft soil in dongting lake area," Geotechnical and Geological Engineering, vol. 38, no. 5, pp. 4995-5003, 2020.

[4] Y. N. Liu and J. F. Lu, "The solution on problem of soft soil layer's collapse in Xin Kailing tunnel and evaluations on its effect," Applied Mechanics and Materials, vol. 90-93, pp. 2401-2407, 2011.

[5] W. Zhao, C. Chen, S. Li, and Y. Pang, "Researches on the influence on neighboring buildings by concave and convex location effect of excavations in soft soil area," Journal of Intelligent \& Robotic Systems, vol. 79, no. 3-4, pp. 351-369, 2015.

[6] B. Li, L. Xiong, L. Zhai et al., "Transparent synthetic soil and its application in modeling of soil-structure interaction using optical system," Frontiers in Earth Science, vol. 7, 2019.

[7] B. Yuan, M. Sun, Y. Wang, L. Zhai, Q. Luo, and X. Zhang, "Full 3D displacement measuring system for 3D displacement field of soil around a laterally loaded pile in transparent soil," International Journal of Geomechanics, vol. 19, no. 5, Article ID 04019028, 2019.

[8] W. Yuan, Z. Li, J. Niu, W. Wang, and J. Li, "Research on a twoparameter reduction method that strictly satisfies the upper and lower limit theorem," Bulletin of Engineering Geology and the Environment, vol. 79, no. 6, pp. 2937-2947, 2020.

[9] W. Yuan, J. Li, Z. Li, W. Wang, and X. Sun, "A strength reduction method based on the Generalized Hoek-Brown (GHB) criterion for rock slope stability analysis," Computers and Geotechnics, vol. 117, Article ID 103240, 2020.

[10] W. Wang, W. Yuan, X.-C Li, and B. Bai, "Evaluation approach of the slope stability based on deformation analysis," International Journal of Geomechanics, vol. 16, no. 2, Article ID 04015054, 2016.

[11] N. Jiang, B. Zhu, X. He, C. Zhou, X. Luo, and T. Wu, "Safety assessment of buried pressurized gas pipelines subject to blasting vibrations induced by metro foundation pit excavation," Tunnelling and Underground Space Technology, vol. 102, Article ID 103448, 2020.

[12] C. F. Zeng, G. Zheng, X. F. Zhou, X. L. Xue, and H. Z. Zhou, "Behaviours of wall and soil during pre-excavation dewatering under different foundation pit widths," Computers and Geotechnics, vol. 115, Article ID 103169, 2019.

[13] Y. F. Chen, Y. Y. Zhu, X. Fan, and Y. L Zhao, "Analytical and experimental analysis of the shear strength of bolted sawtooth joints," European Journal of Environmental and Civil Engineering, vol. 24, pp. 1-15, 2020.

[14] B. Yuan, K. Xu, Y. Wang, R. Chen, and Q. Luo, "Investigation of deflection of a laterally loaded pile and soil deformation using the PIV technique," International Journal of Geomechanics, vol. 17, no. 6, 2017.

[15] Y. X. Wang, P. P. Guo, W. X. Ren et al., "Laboratory investigation on strength characteristics of expansive soil treated with jute fiber reinforcement," International Journal of Geomechanics, vol. 17, no. 11, 2017.

[16] H. Sun, Y. Chen, J. Zhang, and T. Kuang, "Analytical investigation of tunnel deformation caused by circular foundation pit excavation," Computers and Geotechnics, vol. 106, pp. 193-198, 2019.

[17] S. Feng, Y. Wu, J. Li, P. Li, Z. Zhang, and D. Wang, "The analysis of spatial effect of deep foundation pit in soft soil areas," Procedia Earth and Planetary Science, vol. 5, pp. 309-313, 2012.

[18] B. Yuan, K. Xu, Y. Wang, R. Chen, and Q. Luo, "Investigation of deflection of a laterally loaded pile and soil deformation using the PIV technique," International Journal of Geomechanics, vol. 17, no. 6, Article ID 04016138, 2016.

[19] D. He, W. Yang, Y. Cheng, and B. Chen, "Effect of anchor layouts on the safety factor and slip surface of slope," Geotechnical and Geological Engineering, vol. 37, no. 2, pp. 1073-1078, 2019.

[20] B. Yuan, M. Sun, L. Xiong, Q. Luo, S. P. Pradhan, and H. Li, "Investigation of 3D deformation of transparent soil around a laterally loaded pile based on a hydraulic gradient model test," Journal of Building Engineering, vol. 28, Article ID 101024, 2020.

[21] W. X. Peng and J. W. Cao, "A view of studies on inflatable anchor," Science and Technology Review, vol. 28, pp. 111-115, 2010.

[22] W. X. Peng, Y. Wang, and J. W. Cao, "Formation and analysis of the numerical simulation element for the inflatable anchor," Geotechnical Investigation \& Surveying, vol. 38, pp. 6-14, 2010.

[23] W. X. Peng and J. W. Cao, "A review of studies on inflatable anchor," Tech Review, vol. 28, pp. 111-115, 2010.

[24] W. X. Peng and Z. H. Chen, "Research on anchorage theory of the multi-bladder-type inflatable anchor," Technology Innovation and Application, vol. 15, pp. 22-25, 2019.

[25] W. X. Peng, X. Zhang, J. J. Mo, Y. Y. Huang, and Y. Q. Quan, "Model test study on bladder-type inflatable anchor," Journal of Hunan University, vol. 42, pp. 93-99, 2015.

[26] H. Lin, H. Yang, Y. Wang, Y. Zhao, and R. Cao, "Determination of the stress field and crack initiation angle of an open flaw tip under uniaxial compression," Theoretical and Applied Fracture Mechanics, vol. 104, Article ID 102358, 2019.

[27] H. Lin, P. Cao, F.-Q. Gong, J.-T. Li, and Y.-L. Gui, "Directly searching method for slip plane and its influential factors based on critical state of slope," Journal of Central South University of Technology, vol. 16, no. 1, pp. 131-135, 2009.

[28] Y. Wang, H. Lin, Y. Zhao, X. Li, P. Guo, and Y. Liu, "Analysis of fracturing characteristics of unconfined rock plate under edge-on impact loading," European Journal of Environmental and Civil Engineering, vol. 24, no. 14, pp. 2453-2468, 2020.

[29] S. Xie, H. Lin, Y. Chen, R. Yong, W. Xiong, and S. Du, "A damage constitutive model for shear behavior of joints based on determination of the yield point," International Journal of Rock Mechanics and Mining Sciences, vol. 128, Article ID 104269, 2020.

[30] H. Lin, Y. Zhu, J. Yang, and Z. Wen, "Anchor stress and deformation of the bolted joint under shearing," Advances in Civil Engineering, vol. 2020, Article ID 3696489, 10 pages, 2020.

[31] Z. Liu, C. Zhang, Y. Zhang, M.-D. Lu et al., "Field test study of under-reamed ground anchorage with capsule in Ningbo area," Rock and Soil Mechanics, vol. 39, pp. 302-308, 2018.

[32] P. Y. Wen, Experimental Research on Bearing Behavior of Underreamed Uplift Anchor Heinan, Zhengzhou University, Zhengzhou, China, 2016. 